\title{
n-Octyltrichlorosilane Modified SAPO-34/PDMS Mixed Matrix Membranes for Propane/Nitrogen Mixture Separation
}

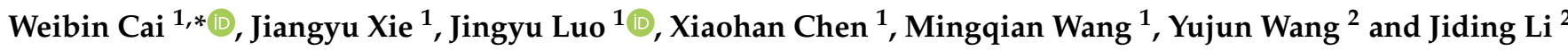 \\ 1 School of Chemical and Environmental Engineering, China University of Mining and Technology, \\ Beijing 100083, China; xjiangyu25@163.com (J.X.); 1910320207@student.cumtb.edu.cn (J.L.); \\ chenxh5175@163.com (X.C.); 18852140162@163.com (M.W.) \\ 2 Department of Chemical Engineering, Tsinghua University, Beijing 100084, China; \\ wangyujun@tsinghua.edu.cn (Y.W.); lijiding@mail.tsinghua.edu.cn (J.L.) \\ * Correspondence: caiweibin@tsinghua.org.cn
}

check for updates

Citation: Cai, W.; Xie, J.; Luo, J.; Chen, X.; Wang, M.; Wang, Y.; Li, J. n-Octyltrichlorosilane Modified SAPO-34/PDMS Mixed Matrix Membranes for Propane/Nitrogen Mixture Separation. Separations 2022, 9, 64. https://doi.org/10.3390/ separations 9030064

Academic Editor:

Victoria Samanidou

Received: 15 January 2022

Accepted: 25 February 2022

Published: 28 February 2022

Publisher's Note: MDPI stays neutral with regard to jurisdictional claims in published maps and institutional affiliations.

Copyright: (c) 2022 by the authors. Licensee MDPI, Basel, Switzerland. This article is an open access article distributed under the terms and conditions of the Creative Commons Attribution (CC BY) license (https:/ / creativecommons.org/licenses/by/ $4.0 /)$.

\begin{abstract}
In this study, zeolite molecular sieve SAPO-34/polydimethylsiloxane (PDMS) mixed matrix membranes (MMMs) were prepared to recover propane. n-Octyltrichlorosilane (OTCS) was introduced to improve compatibility between SAPO-34 and PDMS, and enhance the separation performance of the MMMs. Physicochemical properties of the MMMs were characterized by scanning electron microscopy (SEM), Fourier transform infrared spectroscopy (FT-IR), X-ray diffraction (XRD) and water contact angle (WCA). Results showed that, after modification, alkyl chains were successfully grafted onto SAPO-34 without changing its crystal structure, particles in the MMMs were evenly distributed in the base film, and the hydrophobicity of the MMMs was enhanced. Moreover, the effects of SAPO-34 filling content, operating pressure, and feed gas concentration on the separation performance was explored. This indicated that the modification with OTCS effectively enhanced the separation performance of SAPO-34/PDMS MMMs. When the filling content of modified SAPO34 was $15 \%$, the maximal separation factor of 22.1 was achieved, and the corresponding propane permeation rate was 101 GPU.
\end{abstract}

Keywords: MMMs; SAPO-34; PDMS; OTCS; propane recovery

\section{Introduction}

Volatile organic compounds (VOCs) are organic compounds that participate in atmospheric photochemical reactions or active chemical substances determined in accordance with relevant regulations that damage human health and the environment [1]. Among them, artificial sources include automobile emissions, petrochemical plants, and tail gas from gas stations [2]. Heavy hydrocarbon components $\left(C_{3}+\right)$ in tail gas should be recovered for both economic and environmental perspectives [3]. In terms of VOC detection, there are carbon-canister-based sampling methods and preconcentrator gas chromatography-mass spectrometry (GC-MS) analysis [4]. In terms of VOC recovery, membrane separation technology has many advantages over conventional techniques, such as high efficiency and energy saving, shorter process flow, and simple operation $[5,6]$. The separation performance of membrane materials is directly related to the recovery efficiency of VOCs. Polymeric membranes formed by glassy polymer and rubbery polymer are a hot spot of research due to its excellent gas permeability and good processability [7]. Glassy polymer membranes are constructed from stiff unsaturated frameworks and bulky side chains [8] such as polyetherimide [9,10], poly (1-trimethylsilyl-1-propyne) [11,12]. Glassy polymer membranes usually have good gas permeability, but highly raw prices, complicated synthesis process and poor chemical stability limit its application in practical production. Rubbery polymer membranes such as polyoctylmethylsiloxane and polydecylmethylsiloxane are all successfully used for the separation of $\mathrm{C}_{3} \mathrm{H}_{8} / \mathrm{CH}_{4}$ [13], and PDMS is often used due to its high permeability and good chemical stability [14]. Although it performs well in the 
pure gas permeation test, performance in actual mixed gas (such as propane/nitrogen) still needs to be improved, especially since the adsorption of hydrocarbons leads to the polymer matrix swelling, and the selectivity of hydrocarbons thereby decreases [15-17].

The mixed matrix membrane that combines the characteristics of organic membrane with inorganic membrane is an effective way to improve the performance of polymer membranes. Key factors for the separation performance improvement of MMMs include the intrinsic properties of the dispersed phase (such as particle size and porosity) and the interface compatibility between the dispersed and continuous phases [18]. Metal organic frameworks (MOFs) are a kind of nanoporous material with ultrahigh porosity, large specific surface area, structural diversity, and functional abundance. In recent years, inorganic particles (such as ZIFs and MIL) have been based on MOFs [19,20] that are widely used in oil and gas separation, achieving good results. Considering the advantages of MOFs in this respect, many scholars introduced MOFs into polymer membranes to prepare mixed matrix membranes, such as introducing ZIF-8 and ZIF-71 into polyimide [21,22], and ZIF-8 into polyethylene oxide [23,24], and all achieved good separation performance of propane and propylene. The introduction of ZIF-8 into PDMS [25,26] has also achieved good propane and nitrogen separation performance. However, the high pollution and high cost in the synthesis of MOFs greatly limits its industrial application. Therefore, it is necessary to find materials that are low-cost, simple to synthesize, and easy to industrialize. The molecular sieve [27] is an aluminosilicate composed of regularly arranged silicon-oxygen tetrahedrons and aluminum-oxygen tetrahedrons. It is named because of its uniform pore size and neat arrangement, which has the function of sieving molecules of different sizes and shapes. The silicon-aluminum phosphate (SAPO-n) molecular sieve is a new type of molecular sieve developed by United Carbide Corporation (UCC) [28]. Among them, SAPO-34 has a strong acidic center, a unique pore structure, and abundant micropores. It is widely used in the fields of tail gas purification and membrane separation [29,30]. SAPO-34 was also successfully applied to polyhexafluoroethylene [31], polyethersulfone [32], polyvinylidene fluoride [33], polyurethane [34], and other polymer membranes. During this research, MMMs were prepared by filling PDMS with SAPO-34 to improve the propane recovery performance of PDMS membrane. One reason for the enhanced separation performance by SAPO-34 may be that the formation of rigidified region at the interface may reduce the free volume of PDMS, and thus reduce the diffusion of nitrogen. SAPO-34 can increase the solubility of propane, which is beneficial to improving the permeation flux of propane. However, SAPO-34 contains many hydroxyl groups and has poor compatibility with PDMS. When it is filled in PDMS to produce a mixed matrix membrane, nonselective voids are formed that adversely impact the separation performance of the membrane $[35,36]$, thereby affecting the separation performance of the membrane. In order to solve this problem, OTCS was introduced to modify SAPO-34. Through the reaction between hydroxyl groups on the surface of SAPO-34 and OTCS, most hydroxyl groups are removed and transformed into lipophilic organic groups, so as to turn the hydrophilic surface of SAPO-34 lipophilic, which makes it compatible with PDMS [37]. The OTCS-modified SAPO-34 was then introduced into the PDMS to prepare SAPO-34 (OTCS)/PDMS MMMs. A propane/nitrogen mixture was employed to study the separation performance of the membrane.

\section{Materials and Methods}

\subsection{Materials}

The PDMS prepolymer (hydroxyl-terminated) with a viscosity of 50,000 $\mathrm{mPa} \cdot \mathrm{s}$ was purchased from Beijing Tongguang Fine Chemical Company (Beijing, China). SAPO-34 molecular sieve (silicon-to-aluminum ratio: 1) was obtained from Tianjin Nankai Catalyst Factory (Tianjin, China). Solvent n-heptane (AR) and n-octyltrichlorosilane (OTCS, AR) were received from Aladdin Reagent Co., Ltd. (Shanghai, China). Catalyst dibutyltin dilaurate (DBTL, AR) was supplied by Sinopharm Chemical Reagent Co., Ltd. (Beijing, China), and the crosslinking agent vinyl triethoxysilane (VMOS, AR) was provided by afaesha (China) Chemical Co., Ltd. (Shanghai, China). PVDF with a molecular weight of 
170,000 was purchased from Shanghai XingYa Co, Ltd. (Shanghai, China). Nitrogen $\left(\mathrm{N}_{2}\right.$, $99.99 \mathrm{vol} \%)$ and propane $\left(\mathrm{C}_{3} \mathrm{H}_{8}, 97 \mathrm{vol} \%\right)$ were used for gas permeation evaluation. All chemicals were used as received.

\subsection{Modification of SAPO-34 with OTCS}

SAPO-34 was first placed in an oven at $100{ }^{\circ} \mathrm{C}$ for $2 \mathrm{~h}$ and cooled to room temperature. Then, $5 \mathrm{~g}$ dry SAPO-34 was dispersed in $25 \mathrm{~g}$ n-heptane and stirred for $1 \mathrm{~h}$, ultrasonically dispersed for $30 \mathrm{~min}$, and stirred again for $1 \mathrm{~h}$. We added $0.9 \mathrm{~g}$ of OTCS to the above solution, stirred for $1 \mathrm{~h}$, and then filtered. The filter cake was washed with n-heptane to remove the residual OTCS and dried under vacuum at $110^{\circ} \mathrm{C}$ for $6 \mathrm{~h}$ in an oven to remove the adsorbed n-heptane from the SAPO-34.

\subsection{SAPO-34/PDMS Mixed Matrix Membrane Preparation}

A certain mass of PDMS prepolymer was dissolved in n-heptane and stirred for $4 \mathrm{~h}$. A certain amount of OTCS modified SAPO-34 was dispersed in n-heptane, stirred for $1 \mathrm{~h}$, and ultrasonically dispersed for $1 \mathrm{~h}$ to obtain a uniformly dispersed solution. The acquired dispersed solution was then added to the above acquired PDMS prepolymer/nheptane solution. After mechanical stirring for $30 \mathrm{~min}$, it was ultrasonically dispersed for $30 \mathrm{~min}$. Certain amounts of cross-linking agent VMOS and catalyst DBTL were added. The membrane was casted after the viscosity of casting solution was large enough.

The PVDF (PVDF-1015) porous support membrane was prepared by nonsolvent induced phase separation (NIPS) [38]. Then, the support membrane was paved on a smooth and dry glass plate, and a square groove of $12 \times 12 \mathrm{~cm}$ was adhered on the surface of PVDF membrane with a certain tape thickness. The prepared casting solution was evenly poured on one side of the groove, and scraped across the surface evenly and uniformly with a glass rod to remove the excess casting solution. The scraped composite film was placed at room temperature for $24 \mathrm{~h}$ to volatilize solvent and cure the PDMS prepolymer; then, it was placed in an oven at $80{ }^{\circ} \mathrm{C}$ for $4 \mathrm{~h}$ to further drying and crosslinking. Different contents of SAPO-34 were added to the PDMS to prepare the MMMs, and SAPO-34 (OTCS)/PDMS MMMs were prepared. SAPO-34 (OTCS) samples in PDMS filled with 0, 1, 5, 10, 15, and 20 wt \% MMMs were named M0, M1, M2, M3, M4, M5, respectively. Figure 1 shows the illustration of modification of the preparation of SAPO-34 (OTCS) membranes.

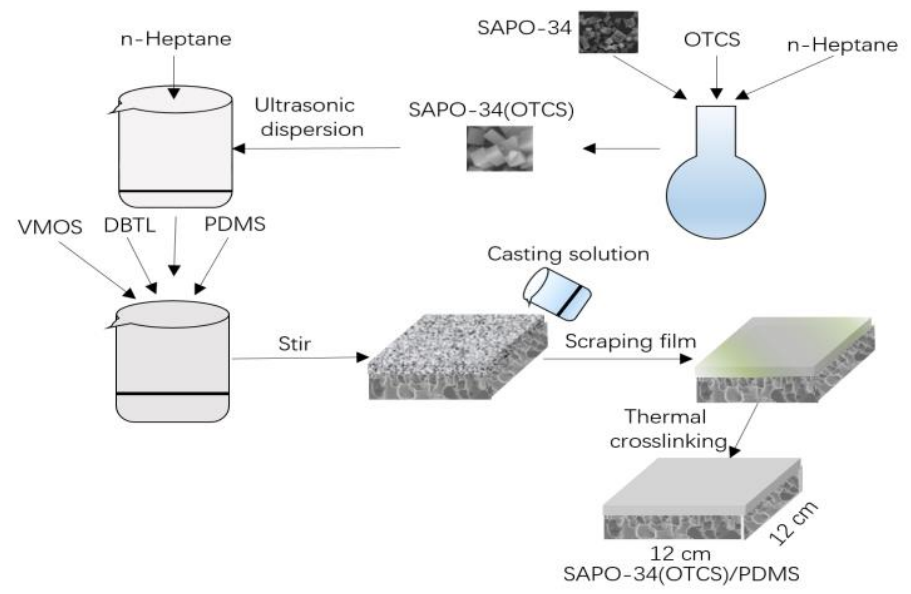

Figure 1. Illustration of preparation of SAPO-34 (OTCS) membranes.

\subsection{Characterization of SAPO-34 and MMMs}

The morphology of SAPO-34 and the prepared MMMs was observed by a scanning electron microscope (JSM7401F). The conductive adhesive was pasted on the sample table, and the SAPO-34 sample was uniformly coated on the surface of the conductive adhesive. For the preparation of cross-sectional samples, membranes were immersed and quenched 
in liquid nitrogen. The sample surface was prepared by shearing clean and dry membrane blocks directly onto the sample table. All samples were tested after vacuum spraying gold.

The infrared spectra of SAPO-34 and prepared MMMs were tested with an IR560 Fourier Transform Infrared Spectrometer from Nicolet, USA, and analyzed by total reflection infrared spectroscopy (FTIR-ATR) with a scanning range of $4000 \sim 600 \mathrm{~cm}^{-1}$ and a scanning resolution of $4 \mathrm{~cm}^{-1}$.

The X-ray diffraction of SAPO-34 granular crystals was tested with Bruker D8 X-ray diffractometer, $\mathrm{Cu} \mathrm{Ka}$ monochromatic filter rays were used, tube voltage was $40 \mathrm{kV}$, scanning rate was $1^{\circ} / \mathrm{min}$, and scanning range was $2^{\circ}-40^{\circ}$.

The static contact angle of pure water on the surface of prepared MMMs was measured at room temperature $\left(25^{\circ} \mathrm{C}\right)$ using an OCA-20 contact angle measuring instrument from German Dataphysics Company; the sample was fixed on a clean and dry glass slide with double-sided tape and cut into a slender strip with a width of $6 \mathrm{~mm}$, and droplet volume was $2 \mu \mathrm{L}$.

\subsection{Gas Permeation Test}

The gas permeation test was carried out in a self-designed device, as shown in Figure 2. The device system consisted of three main parts: gas circuit, membrane device, and gas chromatography. Gas flow was measured by soap film flowmeter. Reference test conditions: total gas flow was $300 \mathrm{~mL} / \mathrm{min}$, reference test temperature was $25^{\circ} \mathrm{C}$, purge gas flow was about $150 \mathrm{~mL} / \mathrm{min}$, the effective area of the membrane tank was about $25 \mathrm{~cm}^{2}$, and the concentration of $\mathrm{C}_{3} \mathrm{H}_{8}$ in the feed gas was $20 \mathrm{vol} \%$.

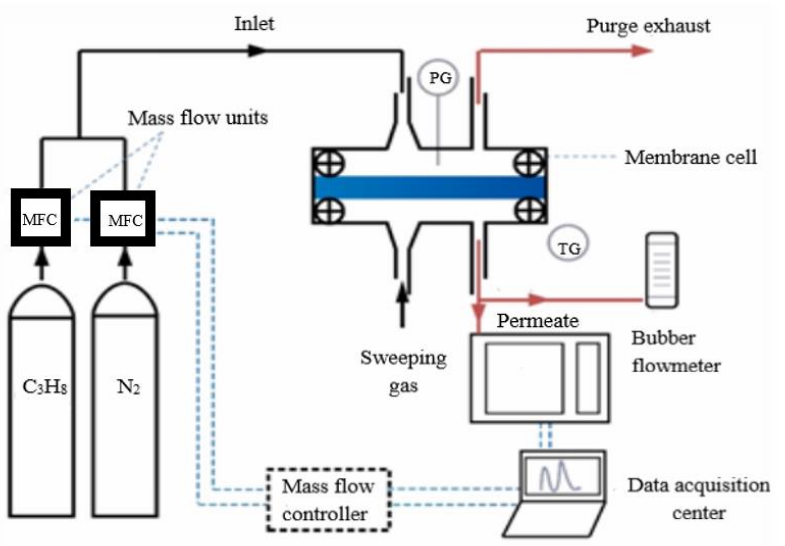

Figure 2. Illustration of membrane performance online evaluation device.

The SAPO-34 (OTCS)/PDMS membrane separation factor was calculated by the following equation:

$$
\beta=\frac{y_{i} / y_{j}}{x_{i} / x_{j}}
$$

where: $x_{i}$ and $y_{i}$ are the volume fractions of component $i$ in the feed gas and permeate gas, respectively.

The permeation rate of component $i, R_{i}\left(\mathrm{GPU}, 1 \mathrm{GPU}=1 \times 10^{-6} \mathrm{~cm}^{3}(\mathrm{STP}) \cdot \mathrm{cm}^{-2} \cdot \mathrm{s}^{-1} \cdot \mathrm{cm} \mathrm{Hg}^{-1}\right)$, was calculated by the following formula:

$$
R_{i}=\frac{Q_{i}}{A \Delta P_{i}}
$$

where $Q_{i}$ is the permeation flux of component $i\left(\mathrm{~cm}^{3} \cdot \mathrm{s}^{-1}\right)$;

$A$ is the actual membrane area, $25 \mathrm{~cm}^{2}$; 
$\Delta P_{i}$ is the partial pressure difference of component $i$ between the upstream and downstream sides of the membrane, which is calculated by Formula (3):

$$
\Delta P_{i}=P_{h} x_{i}-P_{l} y_{i}
$$

where $P_{h}$ is the absolute pressure of the feed gas, and $P_{l}$ is the absolute pressure of the permeate gas.

\section{Results and Discussion}

\subsection{SAPO-34 Molecular Sieve Characterization}

Figure 3 shows that the SAPO-34 crystals were regular in shape, with a cubic hexahedral structure and a particle size of about $3 \mu \mathrm{m}$; after OTCS modification, the crystal structure of SAPO-34 did not change. Figure 4 shows the infrared and XRD spectra of SAPO-34. After modification, the characteristic absorption peaks of $-\mathrm{CH}_{3}$ and $-\mathrm{CH}_{2}$ appeared at 2850-3000 $\mathrm{cm}^{-1}$, which indicated that alkyl chains were successfully grafted onto SAPO-34. The XRD image shows that OTCS modification did not change or destroy the original crystal structure of the SAPO-34, and no new phase was formed.
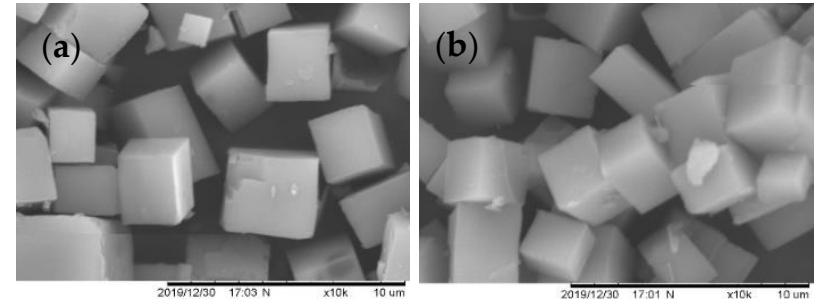

Figure 3. SEM of (a) SAPO-34 and (b) OTCS-modified SAPO-34.
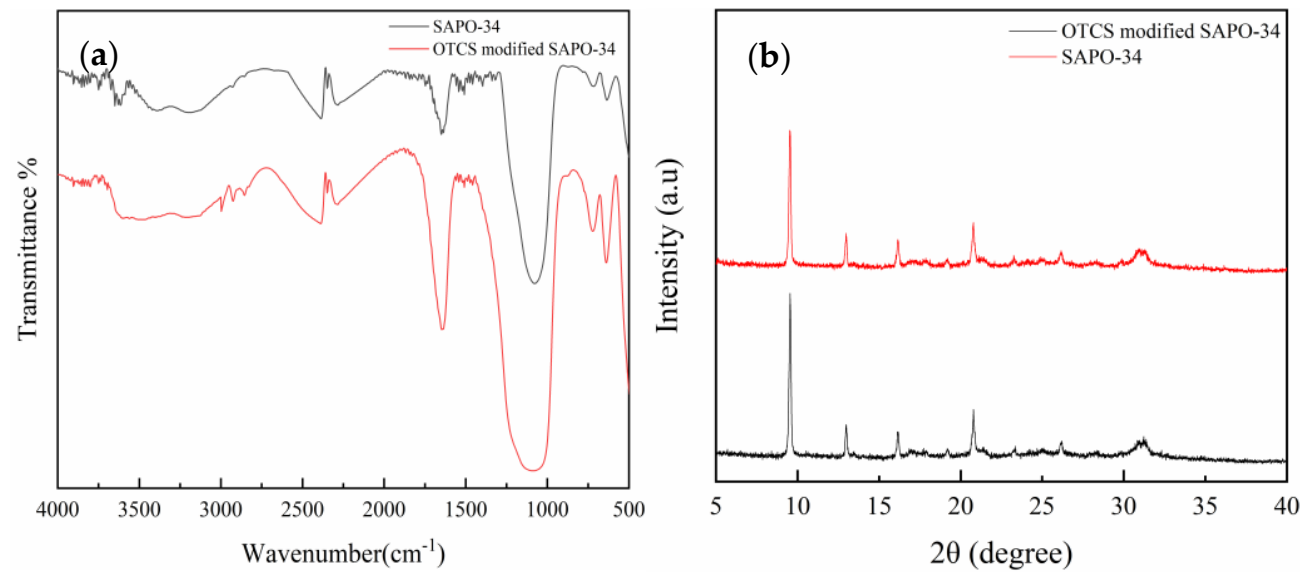

Figure 4. (a) FT-IR spectra and (b) XRD of SAPO-34 and OTCS modified SAPO-34.

\subsection{Morphology of SAPO-34/PDMS MMMs}

Figures 5 and 6 show the surface and cross-sectional morphology of M0-M5. The surface of the pristine PDMS membrane was smooth and flat. With the introduction of SAPO-34, particles began to appear on the membrane surface, and with more SAPO-34 filling, more particles appeared on the membrane surface, and the rougher the surface became. When the filling content was less than $20 \mathrm{wt} \%$, SAPO-34 had good dispersion and no obvious agglomeration, and the surface of MMMs had no obvious defects because the hydroxyl groups on the surface of the modified SAPO-34 were replaced by alkyl chains in the coupling agent reaction, which turned SAPO-34 from hydrophilic into hydrophobic, thus enhancing its compatibility with PDMS. Cross-sectional images show a series of composite membrane structures. The upper layer had a certain degree of pore intrusion, 
which could more firmly bond the separation layer and basement membrane, and the thickness of the PDMS separation layer was about $12 \mu \mathrm{m}$.

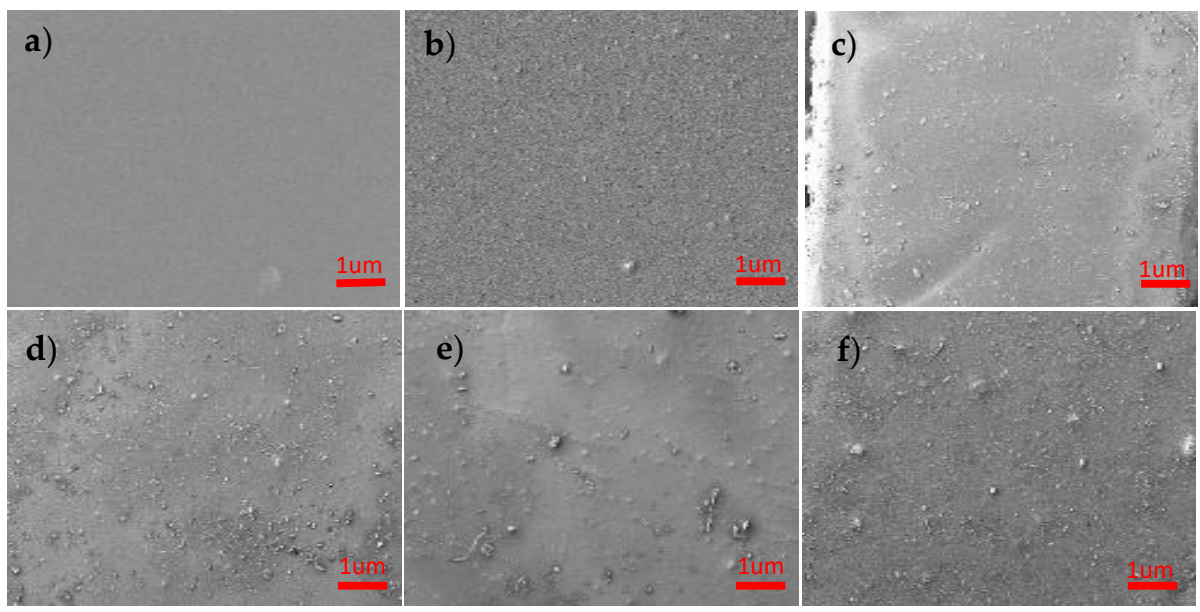

Figure 5. SEM images of surface of membranes ((a): M0, (b): M1, (c): M2, (d): M3, (e): M4, (f): M5).

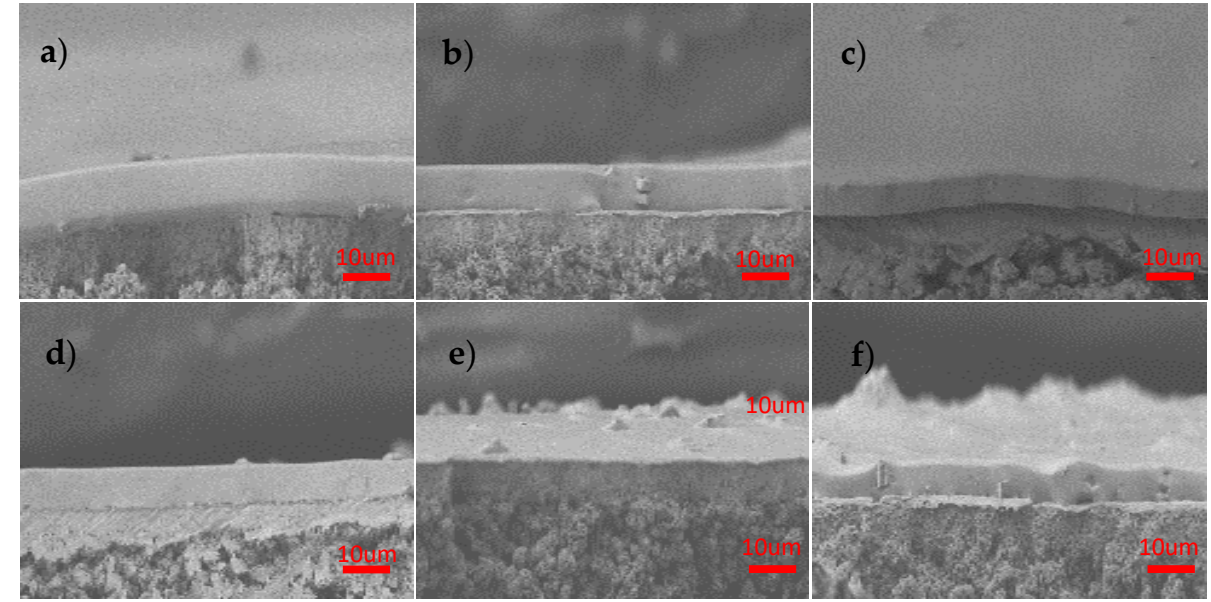

Figure 6. SEM image of cross-section of membranes. ((a) M0; (b) M1; (c) M2; (d) M3; (e) M4; (f) M5).

FT-IR spectra of the PMDS prepolymer and MMMs are shown in Figure 7a. The characteristic absorption peaks at $3000-2890 \mathrm{~cm}^{-1}$ were generated by the stretching of $\mathrm{Si}-\mathrm{OH}$ groups and the stretching vibration of $-\mathrm{CH} 3$ groups in PDMS; $1200-1300 \mathrm{~cm}^{-1}$ resulted from the deformation vibration of $\mathrm{Si}-\mathrm{C}$ groups; $1000-1150 \mathrm{~cm}^{-1}$ occurred from the angle bending vibration of $\mathrm{Si}-\mathrm{OH}$ groups and the asymmetric stretching of $\mathrm{Si}-\mathrm{O}-\mathrm{Si}$ groups [38-40]. The PDMS used in this work was hydroxyl-terminated, and most of the hydroxyl groups were consumed after the cross-linking reaction. Comparing with the PDMS prepolymer, the peak intensity of the cross-linked membrane was significantly weakened. With the increase in SAPO-34 content, peak intensity had no obvious change because the hydroxyl group of SAPO-34 was greatly reduced, which had little promotion on PDMS cross-linking. Figure $7 \mathrm{~b}$ shows the contact angle of prepared MMMs with different SAPO-34 (OTCS) loading (M0-M5). With the increase in filling content, the surface contact angle of the MMMs increased, which indicated that the surface hydrophobicity of MMMs increased. The reasons are as follows: On the one hand, the SAPO-34 particles are hydrophobic. After modification, the hydroxyl groups on the surface of the SAPO-34 decreased, and organic functional groups increased, which increased the hydrophobicity of the MMMs. On the other hand, the filling of SAPO-34 (OTCS) increased the surface roughness of the membrane, which is beneficial for increasing the contact angle for hydrophobic surfaces [37]. 

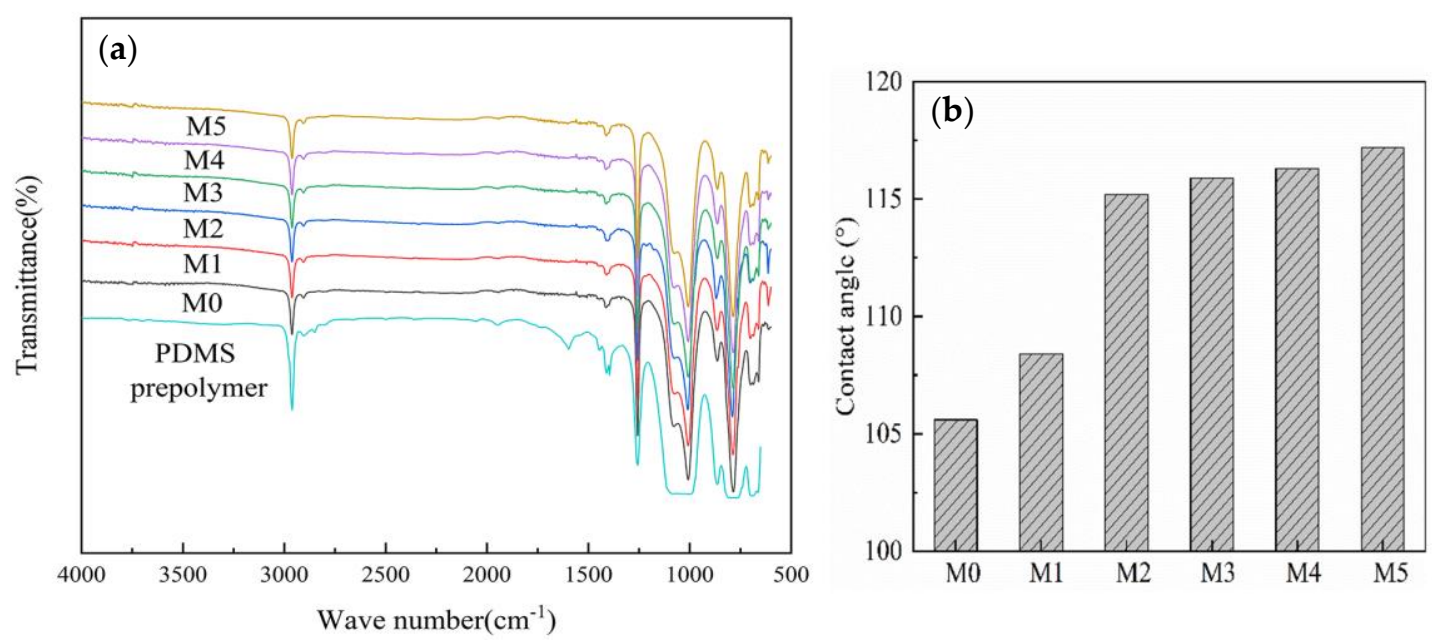

Figure 7. (a) FT-IR spectra of PMDS prepolymer and M0-M5; (b) contact angles of M0-M5.

\subsection{Separation Performance of SAPO-34 (OTCS)/PDMS MMMs}

\subsubsection{Effect of OTCS Modification}

The separation performance of MMMs with SAPO-34 and OTCS-modified SAPO-34 is shown in Table 1 . The filling content was 5\%, and the test was carried out at $0.1 \mathrm{MPa}$. The separation factor and propane permeance of the mixed matrix membrane were significantly higher for the SAPO-34 (OTCS)/PDMS MMMs, which shows that the separation performance of the mixed matrix membrane could be effectively improved after modification. Therefore, SAPO-34 modified by OTCS was used in the later part of the work.

Table 1. Separation performance of the MMMs filled with SAPO-34 and OTCS-modified SAPO-34.

\begin{tabular}{ccc}
\hline & Separation Factors & Propane Permeance \\
\hline SAPO-34/PDMS MMMs & 14.2 & 97.7 \\
SAPO-34 (OTCS)/PDMS MMMs & 18.8 & 139.0 \\
\hline
\end{tabular}

\subsubsection{Effect of SAPO-34 (OTCS) Loading}

Figure 8 shows the separation factors and propane permeance of MMMs at different SAPO-34 (OTCS) loading. The separation factor of the membrane first increased with the increase of SAPO-34 (OTCS) loading, reached the maximal value of 22.1 when the loading was $15 \%$, and then decreased rapidly with the increase of loading. SAPO-34 was modified by OTCS, leading to the MMMs having a certain solubilization effect on organic vapor [41,42], which increased the solubility of propane in the MMMs and thus helped in improving the separation factor of the membrane. When the SAPO-34 (OTCS) loading exceeded 15\%, as Figure 6 shows, the agglomeration of SAPO-34 (OTCS) increased significantly, resulting in internal voids and mesoporous defects. The defect had no preferential selectivity to propane, resulting in a decrease in the separation factor of MMM [43,44]. In terms of propane permeance, when the filling content was between 0 and $15 \%$, the propane permeation rate decreased with the increase in SAPO-34 (OTCS) loading. PDMS segments are extremely flexible and have strong mobility, which is conducive to gas permeation. With the filling of nanoparticles, the motion of the segments at the interface is affected by nanoparticles, tending to be regular and closely arranged, forms the so-called "chain rigidification", and further reduces gas permeability [41,45-47]. M Nour [48] filled carbon nanotubes into PDMS, and I Hossain et al. [49] added $\mathrm{NH}_{2}-\mathrm{UIO}-66$ to PDMS, resulting in a decline in permeation rate. While the loading reached $20 \%$, propane permeance increased due to the defects caused by the partial agglomeration of the SAPO-34. The $15 \%$ loading of SAPO-34 (OTCS) showed the best separation factor and appropriate propane permeation. 


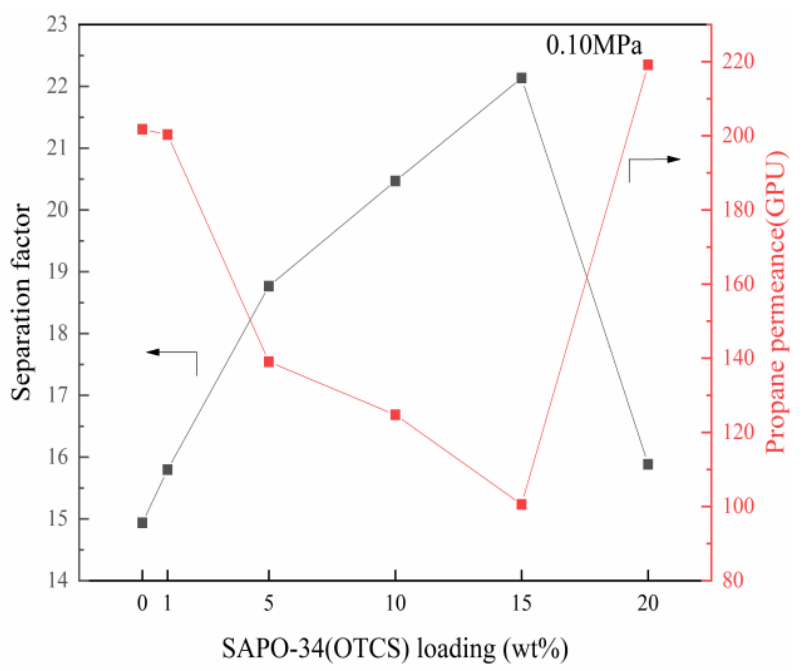

Figure 8. Effects of SAPO-34 (OTCS) loading on separation performance.

\subsubsection{Effect of Operating Pressure}

Figure 9 shows the effect of different operating pressures on the separation factor and the propane permeance. As operating pressure increased, the separation factor of the MMMs decreased. The reason may be that the solubility of propane in PDMS increased, which increased the swelling degree and free volume of PDMS, and the increase in free volume should be more conducive to the penetration of nitrogen. When the loading was $5 \%-15 \%$, the separation factor was basically more than 16.0 , and the maximum was 22.1 . With the increase in operating pressure, the propane permeance of the membrane increased. For all the loading in this work, propane permeance remained above 100 GPU, which is considered to have industrial feasibility [50]. Through a reasonable process design, the silicone rubber membrane with a separation factor of 10 and permeation of more than 100 GPU can effectively concentrate the alkane to more than $99 \%$. According to different feed-permeate side pressure ratios, it is often necessary to select membrane materials with different permeability and selectivity for combination in order to optimize the operating cost as much as possible [51]. Therefore, the highly selective SAPO-34 (OTCS)/PDMS MMMs prepared in this paper provides more choice for industrial application. In industrial application, certain operating pressure can be selected according to separation requirements to obtain appropriate flux and separation factor.
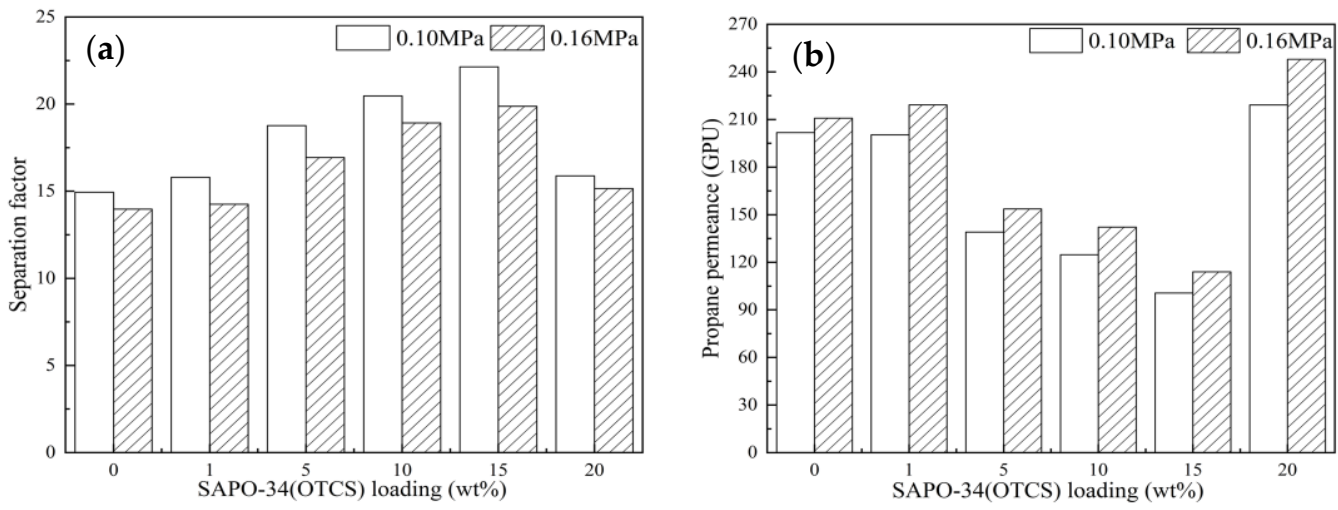

Figure 9. Effects of operating pressures of different SAPO-34 (OTCS) loading of membranes on separation factors (a) and propane permeance (b) in propane concentration of $20 \mathrm{vol} \%$.

\subsubsection{Effect of Propane Feed Concentration}

In industrial applications, due to the limitation of separation factors, one-stage membrane separation always cannot concentrate the hydrocarbon (propane) to the required 
concentration; in this case, multistage membrane concentration is required. The concentration of hydrocarbon in the permeate was high, thus affecting the subsequent separation. Therefore, the effect of concentration on the separation performance was studied. Figure 10 shows the effect of propane feed concentration on the separation performance of M4. As the concentration of propane in the feed gas increases, the permeation rate of propane and nitrogen both increase. When the propane feed concentration increased from 10 to $20 \mathrm{vol} \%$, the permeation of propane increased greatly from 70 to 102 GPU and then slowed down with the further increase in feed concentration. This is similar to Fang's work [52]. The reason can be ascribed to the increased propane dissolved in PDMS at high feed concentration, which promotes propane permeance. However, when the feed concentration exceeded $20 \mathrm{vol} \%$, possibly due to the propane equilibrium uptake in the MMMs, the grow rate propane permeance declined. For nitrogen, as propane dissolved in the membrane increased, the free volume of PDMS also increased, which is beneficial to nitrogen diffusion, so the permeation rate continued to increase. As a result, separation factor showed a decreasing trend. When feed propane concentration increased to $40 \mathrm{vol} \%$, propane in the permeate was enriched to more than $90 \mathrm{vol} \%$. In general, propane concentration has a certain effect on the separation factor, but it is not significant. When propane concentration exceeds $20 \%$, influence on the permeance of propane and nitrogen is limited. If a multistage membrane separation process is used, propane with even higher purity can easily be obtained.
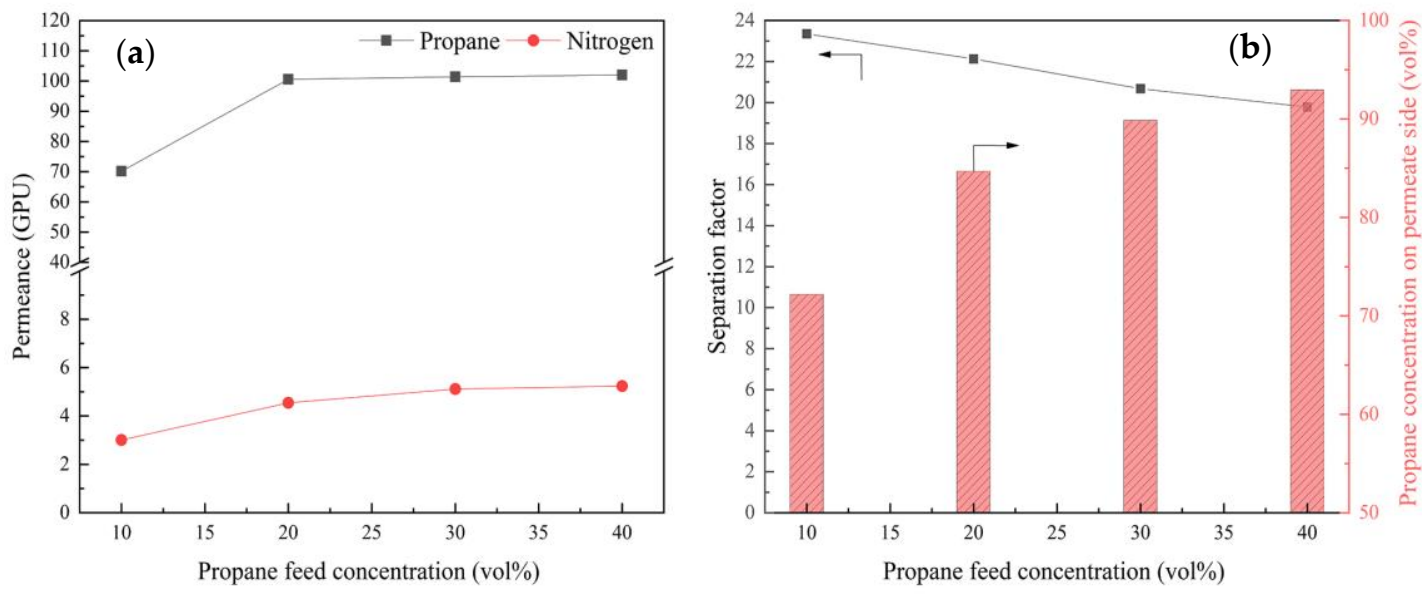

Figure 10. Effect of propane feed concentration on (a) separation factors and (b) propane permeance on operating pressure at $0.10 \mathrm{MPa}$.

\section{Conclusions}

In this paper, SAPO-34 was modified by OTCS and then blended with PDMS to prepare a SAPO-34 (OTCS)/PDMS mixed matrix membrane. SEM, FT-IR, XRD and other characterizations revealed that the crystal structure of SAPO-34 did not change after modification, and OTCS was successfully grafted. The surface roughness and hydrophobicity of the prepared membrane increased with the filling of SAPO-34, which was beneficial to the dissolution of propane. A small amount of SAPO-34 agglomeration occurred only when the loading was over to $20 \mathrm{wt} \%$. When the loading of SAPO-34 (OTCS) was 15\%, separation factor reached 22.1, and propane permeance was 101 GPU. Compared with the unfilled membrane, the overall separation performance of SAPO-34 (OTCS)-filled PDMS membrane was greatly improved.

In conclusion, SAPO-34 (OTCS)/PDMS MMMs have low preparation cost and good separation factor. However, if the permeation flux could be further improved, it would be more conducive to its application. One way is to reduce the size of SAPO-34 powder, so that the separation layer of the MMMs is thinner, which is conducive to improving the flux. The mechanism of separation enhancement by inorganic powder is not well-understood, 
so if the work in this field is strengthened, it is possible to develop more suitable zeolites and modifiers; thus, the separation performance of the MMMs can be effectively improved.

Author Contributions: Data collation, J.X. and J.L. (Jingyu Luo); formal analysis, J.X., J.L. (Jingyu Luo) and X.C.; funding acquisition, W.C., J.L. (Jiding Li); investigation, J.X., X.C. and M.W.; methodology, W.C., J.X., J.L. (Jingyu Luo) and M.W.; project management, W.C., Y.W. and J.L. (Jiding Li); writing-original draft, J.X.; writing-reviewing and editing, W.C., Y.W. and J.L. (Jiding Li). All authors have read and agreed to the published version of the manuscript.

Funding: This work was supported by National Natural Science Foundation of China (no. 21736001), State Key Laboratory of Chemical Engineering (no. SKL-ChE-20A03), Fundamental Research Funds for the Central Universities (2021YJSHH16), and the National Training Program of Innovation and Entrepreneurship for Undergraduates (202103056).

Institutional Review Board Statement: Not applicable.

Informed Consent Statement: Not applicable.

Conflicts of Interest: There are no conflicts of interest to declare.

\section{References}

1. Li, B.; Ho, S.S.H.; Gong, S.; Ni, J.; Li, H.; Han, L.; Yang, Y.; Qi, Y.; Zhao, D. Characterization of VOCs and their related atmospheric processes in a central Chinese city during severe ozone pollution periods. Atmos. Chem. Phys. 2019, 19, 617-638. [CrossRef]

2. Song, M.; Liu, X.; Zhang, Y.; Shao, M.; Lu, K.; Tan, Q. Sources and abatement mechanisms of VOCs in southern china. Atmos. Environ. 2019, 201, 28-40. [CrossRef]

3. Yang, Y.; Ji, D.; Sun, J.; Wang, Y.H.; Yao, D. Ambient volatile organic compounds in a suburban site between Beijing and Tianjin: Concentration levels, source apportionment and health risk assessment. Sci. Total Environ. 2019, 695, 133889. [CrossRef] [PubMed]

4. Hoisington, J.; Herrington, J.S. Rapid Determination of Ethylene Oxide and 75 VOCs in Ambient Air with Canister Sampling and Associated Growth Issues. Separations 2021, 8, 35. [CrossRef]

5. Li, X.; Zhang, L.; Yang, Z.Q.; Wang, P.; Yan, Y.F.; Ran, J.Y. Adsorption materials for volatile organic compounds (VOCs) and the key factors for VOCs adsorption process: A review. Sep. Purif. Technol. 2020, 235, 116213. [CrossRef]

6. Bernardo, P.; Drioli, E.; Golemme, G. Membrane Gas Separation: A Review/State of the Art. Ind. Eng. Chem. Res. 2009, 48, 4638-4663. [CrossRef]

7. Muntha, S.T.; Kausar, A.; Siddiq, M. Progress in Applications of Polymer-Based Membranes in Gas Separation Technology. Polym. Plast. Technol. Eng. 2016, 55, 1282-1298. [CrossRef]

8. Iyer, G.M.; Liu, L.; Zhang, C. Hydrocarbon separations by glassy polymer membranes. J. Polym. Sci. 2020, 58, 2482-2517. [CrossRef]

9. Alqaheem, Y.; Alomair, A.; Alhendi, A.; Alkandari, S. Preparation of polyetherimide membrane from non-toxic solvents for the separation of hydrogen from methane. Chem. Cent. J. 2018, 12, 80. [CrossRef]

10. Khan, M.Y.; Khan, A.; Adewole, J.K.; Naim, M.; Basha, S.I.; Aziz, M.A. Biomass derived carboxylated carbon nanosheets blended polyetherimide membranes for enhanced $\mathrm{CO}_{2} / \mathrm{CH}_{4}$ separation. J. Nat. Gas Sci. Eng. 2020, 75, 103156. [CrossRef]

11. Feng, H.; Hong, T.; Mahurin, S.M.; Vogiatzis, K.D. Gas separation mechanism of $\mathrm{CO}_{2}$ selective amidoxime-poly(1-trimethylsilyl1-propyne) membranes. Polym. Chem. 2017, 8, 3341-3350. [CrossRef]

12. Kossov, A.A.; Litvinova, E.G.; Ezhov, A.A.; Khotimskii, V.S.; Shishatskii, S.M.; Buhr, K. Copolymers of 1-(3,3,3Trifluoropropyldimethylsilyl)-1-Propyne with 1-Trimethylsilyl-1-Propyne as Membrane Materials for Separation of Gas Mixtures Containing Hydrocarbons. Petrol. Chem. 2018, 58, 1123-1128. [CrossRef]

13. Grushevenko, E.A.; Borisov, I.L.; Bakhtin, D.S.; Bondarenko, G.N.; Levin, I.S.; Volkov, A.V. Silicone rubbers with alkyl side groups for C3+ hydrocarbon separation. React. Funct. Polym. 2019, 134, 156-165. [CrossRef]

14. Yang, J.; Vaidya, M.M.; Harrigan, D.J.; Duval, S.A.; Hamad, F. Modified rubbery siloxane membranes for enhanced C $3+$ hydrocarbon recovery from natural gas: Pure and multicomponent gas permeation evaluation. Sep. Purif. Technol. 2020, 242, 116774. [CrossRef]

15. Prajapati, P.K.; Kansara, A.M.; Aswal, V.K.; Singh, P.S. High oxygen permeable Zeolite poly(dimethylsiloxane) membrane for air separation. J. Appl. Polym. Sci. 2019, 136, 48047. [CrossRef]

16. Sander, R.; Reijerkerk, M.H.; Knoef, K.N.; Matthias, W. Poly (ethylene glycol) and poly (dimethyl siloxane): Combining their advantages into efficient $\mathrm{CO}_{2}$ gas separation membranes. J. Membr. Sci. 2010, 352, 126-135.

17. Belov, N.A.; Tarasenkov, A.N.; Tebeneva, N.A.; Vasilenko, N.G.; Shandryuk, G.A.; Yampolskii, Y.P.; Muzafarov, A.M. Synthesis and Gas-Transport Properties of Iron- and Zirconium-Containing Polydimethylsiloxanes. Polymer. Sci. 2018, 60, 405-413. [CrossRef]

18. Liu, H.; Wang, N.; Zhao, C.; Ji, S.; Li, J. Membrane materials in the pervaporation separation of aromatic/aliphatic hydrocarbon mixtures-A review. Chin. J. Chem. Eng. 2018, 26,1-16. [CrossRef]

19. Zhang, Y.; Feng, X.; Yuan, S.; Zhou, J.; Wang, B. Challenges and recent advances in MOF-polymer composite membranes for gas separation. Inorg. Chem. Front. 2016, 3, 896-909. [CrossRef] 
20. Fang, M.; Zhang, G.; Liu, Y.; Xiong, R.; Wu, W.; Yang, F.; Liu, L.; Chen, J.; Li, J. Exploiting Giant-Pore Systems of Nanosized MIL-101 in PDMS Matrix for Facilitated Reverse-Selective Hydrocarbon Transport. ACS Appl. Mater. Interfaces 2020, 12, 1511-1522. [CrossRef]

21. Zhang, C.; Dai, Y.; Johnson, J.R.; Karvan, O.; Koros, W.J. High performance ZIF-8/6FDA-DAM mixed matrix membrane for propylene/propane separations. J. Membr. Sci. 2012, 389, 34-42. [CrossRef]

22. Japip, S.; Wang, H.; Xiao, Y.; Chung, T. Highly permeable zeolitic imidazolate framework (ZIF)-71 nano-particles enhanced polyimide membranes for gas separation. J. Membr. Sci. 2014, 467, 162-174. [CrossRef]

23. Yang, F.; Mu, H.; Wang, C.; Xiang, L.; Yao, K.; Liu, L.; Yang, Y.; Han, Y.; Li, Y.; Pan, Y. Morphological Map of ZIF-8 Crystals with Five Distinctive Shapes: Feature of Filler in Mixed-Matrix Membranes on $\mathrm{C}_{3} \mathrm{H}_{6} / \mathrm{C}_{3} \mathrm{H}_{8}$ Separation. Chem. Mater. 2018, 30, 3467-3473. [CrossRef]

24. Liu, D.; Xiang, L.; Chang, H.; Chen, K.; Wang, C.; Pan, Y.; Li, Y.; Jiang, Z. Rational matching between MOFs and polymers in mixed matrix membranes for propylene/propane separation. Chem. Eng. Sci. 2019, 204, 151-160. [CrossRef]

25. Yuan, J.; Li, Q.; Shen, J.; Huang, K.; Liu, G.; Zhao, J.; Duan, J.; Jin, W. Hydrophobic-functionalized ZIF-8 nanoparticles incorporated PDMS membranes for high-selective separation of propane/nitrogen. Asia-Pac. J. Chem. Eng. 2017, 12, 110-120. [CrossRef]

26. Fang, M.; Wu, C.; Yang, Z.; Wang, T.; Xia, Y.; Li, J. ZIF-8/PDMS mixed matrix membranes for propane/nitrogen mixture separation: Experimental result and permeation model validation. J. Membr. Sci. 2015, 474, 103-113. [CrossRef]

27. Heck, H.H.; Hall, M.L.; Santos, R.D.; Tomadakis, M.M. Pressure swing adsorption separation of $\mathrm{H}_{2} \mathrm{~S} / \mathrm{CO}_{2} / \mathrm{CH}_{4}$ gas mixtures with molecular sieves 4A, 5A, and 13X. Sep. Sci. Technol. 2017, 53, 1-8. [CrossRef]

28. Kosinov, N.; Gascon, J.; Kapteijn, F.; Hensen, E.J.M. Recent developments in zeolite membranes for gas separation. J. Membr. Sci. 2015, 499, 65-79. [CrossRef]

29. Henninger, S.K.; Ernst, S.J.; Gordeeva, L.; Bendix, P.; Frohlich, D. New materials for adsorption heat transformation and storage. Renew. Energ. 2017, 110, 59-68. [CrossRef]

30. Carreon, M.A. Molecular sieve membranes for $\mathrm{N}_{2} / \mathrm{CH}_{4}$ separation. J. Mater. Res. 2018, 33, 32-43. [CrossRef]

31. Santaniello, A.; Renzo, A.D.; Maio, F.D.; Belov, N.A.; Yampolskii, Y.P.; Golemme, G. Competing non ideal behaviour of SAPO-34 and Poly(hexafluoropropylene) in mixed matrix membranes. Micropor. Mesopor. Mat. 2020, 303, 110241. [CrossRef]

32. Haider, B.; Dilshad, M.R.; Rehman, M.A.U.; Schmitz, J.V.; Kaspereit, M. Highly permeable novel PDMS coated asymmetric polyethersulfone membranes loaded with SAPO-34 zeoilte for carbon dioxide separation. Sep. Sci. Technol. 2020, $248,116899$.

33. Ahmad, N.A.; Leo, C.P.; Ahmad, A.L.; Izwanne, M.N. Swelling reduction of polyvinylidenefluoride hollow fiber membrane incorporated with silicoaluminophosphate-34 zeotype filler for membrane gas absorption. Sep. Sci. Technol. 2018, 212, 941-951. [CrossRef]

34. Sodeifian, G.; Raji, M.; Asghari, M.; Rezakazemi, M.; Dashti, A. Polyurethane-SAPO-34 mixed matrix membrane for $\mathrm{CO}_{2} / \mathrm{CH}_{4}$ and $\mathrm{CO}_{2} / \mathrm{N}_{2}$ separation. Chin. J. Chem. Eng. 2019, 27, 322-334. [CrossRef]

35. Chua, L.K.; Jusoh, N.J.; Yeong, Y.F. Fabrication of SAPO-34 and Silane-modified SAPO-34/Polyimide Mixed Matrix Membranes for $\mathrm{CO}_{2} / \mathrm{CH}_{4}$ Separation. J. Appl. Sci. Agric. 2015, 10, 215-221.

36. Chung, T.S.; Jiang, L.Y.; Li, Y.; Kulprathipanja, S. Mixed matrix membranes (MMMs) comprising organic polymers with dispersed inorganic fillers for gas separation. Prog. Polym. Sci. 2007, 32, 482-507. [CrossRef]

37. Zhan, X.; Li, J.D.; Fang, C.; Han, X.L. Pervaporation separation of ethanol/water mixtures with chlorosilane modifird silicalite1/PDMS hybrid membranes. Chin. J. Polym. Sci. 2010, 28, 625-635. [CrossRef]

38. Cai, W.B.; Sun, Y.Z.; Piao, X.L.; Li, J.D.; Zhu, S.L. Solvent recovery from soybean oil/Hexane Miscella by PDMS Composite Membrane. Chin. J. Chem. Eng. 2011, 19, 575-580. [CrossRef]

39. Liu, L.L.; Han, X.L.; Hu, W.L.; Zhao, B.X.; Fan, A. Desulfurization Performance of Polydimethylsiloxane Membranes by Pervaporation: Effect of Cross-linking Agents. Polym. Eng. Sci. 2017, 57, 1127-1135. [CrossRef]

40. Jafarinasab, M.; Barzin, J.; Mortaheb, H.R.; Mobedi, H. Structure and performance characterization of PDMS/PES-based pervaporation membranes for ethanol/water separation. Iran. Polym. J. 2015, 24, 989-1002. [CrossRef]

41. Li, Y.; Chung, T.-S.; Cao, C.; Kulprathipanja, S. The effects of polymer chain rigidification, zeolite pore size and pore blockage on polyethersulfone (PES)-zeolite A mixed matrix membranes. J. Membr. Sci. 2005, 260, 45-55. [CrossRef]

42. Li, Y.; Guan, H.-M.; Chung, T.-S.; Kulprathipanja, S. Effects of novel silane modification of zeolite surface on polymer chain rigidification and partial pore blockage in polyethersulfone (PES)-zeolite A mixed matrix membranes. J. Membr. Sci. 2006, 275, 17-28. [CrossRef]

43. Zhao, D.; Ren, J.Z.; Li, H.; Hua, K.S.; Deng, M. Poly (amide-6-b-ethylene oxide)/SAPO-34 mixed matrix membrane for CO 2 separation. J. Energy Chem. 2014, 23, 227-234. [CrossRef]

44. Moore, T.T.; Koros, W.J. Non-ideal effects in organic-inorganic materials for gas separation membranes. J. Mol. Struct. 2005, 739, 87-98. [CrossRef]

45. Klonos, P.; Panagopoulou, A.; Bokobza, L.; Kyritsis, A.; Peoglos, V.; Pissis, P. Comparative studies on effects of silica and titania nanoparticles on crystallization and complex segmental dynamics in poly (dimethylsiloxane). Polymer 2010, 51, 5490-5499. [CrossRef]

46. Ebengou, R.; Cohen-Addad, J. Silica-poly (dimethylsiloxane) mixtures: n.m.r. approach to the crystallization of adsorbed chains. Polymer 1994, 35, 2962-2969. [CrossRef]

47. Aranguren, M.I. Crystallization of polydimethylsiloxane: Effect of silica filler and curing. Polymer 1998, 39, 4897-4903. [CrossRef] 
48. Nour, M.; Berean, K.; Balendhran, S.; Jian, Z.O.; Plessis, J.D. CNT/PDMS composite membranes for $\mathrm{H}_{2}$ and $\mathrm{CH}_{4}$ gas separation. Int. J. Hydrogen Energy 2013, 38, 10494-10501. [CrossRef]

49. Hossain, I.; Husna, A.; Chaemchuen, S.; Verpoort, F.; Kim, T.H. Cross-Linked Mixed-Matrix Membranes Using Functionalized UiO- 66- $\mathrm{NH}_{2}$ into PEG/PPGPDMS-Based Rubbery Polymer for Efficient $\mathrm{CO}_{2}$ Separation. ACS Appl. Mater. Interfaces 2020, 12, 57916-57931. [CrossRef]

50. Baker, R.W.; Wijmans, J.G.; Kaschemekat, J.H. The design of membrane vapor-gas separation systems. J. Membr. Sci. 1998, 151, 55-62. [CrossRef]

51. Huang, Y.; Merkel, T.C.; Baker, R.W. Pressure ratio and its impact on membrane gas separation processes. J. Membr. Sci. 2014, 463, 33-40. [CrossRef]

52. Fang, M.; Zhang, H.; Chen, J.; Tao, W.; Cao, X. A facile approach to construct hierarchical dense membranes via polydopamine for enhanced propylene/nitrogen separation. J. Membr. Sci. 2016, 499, 290-300. [CrossRef] 